\title{
MEANDROS POLÍTICOS E LITERÁRIOS DE ERICO VERISSIMO EM PORTUGAL
}

\section{Fernanda Boarin Boechat ${ }^{1}$}

Resumo: No presente artigo, nossa atenção se volta ao relato do escritor Erico Verissimo sobre sua estadia em Portugal no ano de 1959, publicado postumamente no Brasil no segundo volume da sua autobiografia, Solo de clarineta, no ano de 1975. O contexto português autoritário de Oliveira Salazar é então recebido pela voz do escritor no contexto autoritário brasileiro. A partir de movimentações e trânsitos migratórios do próprio escritor, discutiremos a dimensão política que assume sua obra e sua atuação no espaço social das relações humanas, de modo que ele se constrói e se consolida em sua carreira também como um intelectual autônomo engajado nas causas particulares em prol de valores universais.

Palavras-chave: Erico Verissimo; autobiografia; intelectual; autoritarismo.

Abstract: In this paper, we turn our attention to the narrative by the writer Erico Verissimo about his stay in Portugal in 1959, which was published posthumously in Brazil in the second volume of his autobiography, Solo de clarineta, in 1975. The Portuguese context of Oliveira Salazar's authoritarianism was received by the writer's voice in the Brazilian authoritarian context. Based on migratory movements and transits by the writer himself, we discuss the political dimension that his work assumes and his performance in the social space of human relations, so that he builds and consolidates himself in his career as an autonomous intellectual engaged in particular causes in support of universal values.

Keywords: Erico Verissimo; autobiography; intellectual; authoritarianism.

1 Professora Adjunta do curso de Licenciatura em Letras Alemão do Instituto de Letras e Comunicação da Universidade Federal do Pará (UFPA). E-mail: fernandaboechat@gmail.com 
As movimentações econômicas e políticas no mundo impulsionam, por consequência, a movimentação de inúmeras pessoas pelo globo. Esses deslocamentos territoriais e sociais, portanto, estão permeados por aspectos econômicos e políticos. Grandes ondas migratórias, como as que se tornam intensas a partir da Segunda Guerra Mundial, são decorrentes também de movimentos precedentes. Assim, aquele cenário dramático culminado na metade dos anos 1940 na Europa e que também afetou diretamente os contextos nas Américas foi sendo desenhado por influências e interesses diversos muito antes do eclodir da referida Guerra.

A relação entre a atuação de intelectuais e artistas, e as movimentações políticas assume protagonismo em diversos contextos históricos, a exemplo mesmo dos anos 1940 e o período específico em que se dão os conflitos armados, seja quando nos detemos a perseguições, prisões e assassinatos ocorridos ou mesmo ao exílio, por vezes a única alternativa de sobrevivência. Ademais, aqueles que se deslocam, e muitas vezes por essa razão encontram espaço para a continuidade de suas obras, promovem também alterações nas constelações em que se inserem.

Nesse sentido, cabe observar que não somente a atuação de artistas e intelectuais em espaços públicos é considerada como movimento político que constrói os cenários em que se inseriram, ou mesmo a recepção e crítica de obras quando produzidas e divulgadas, mas também identificar em que medida há uma cadeia de recepções que se dá de modo síncrono e assíncrono, uma vez que a obra perpetua e é recebida também em momentos históricos posteriores. Além disso, não seria também a experiência atual do artista material e referência para a concepção posterior de obras a serem recebidas em outro momento oportuno?

A respeito de tais considerações, partiremos no presente artigo da relação entre o trânsito, o movimento e deslocamento também migratório de Erico Verissimo e de sua obra. Aqui nos voltaremos em especial à atuação política do autor em momentos específicos, construída desde o início da carreira nos anos 1930 na Editora Globo, intensificada por meio da sua atuação junto à política de Boa Vizinhança estadunidense nos anos $1940^{2}$ e a posterior estadia no mesmo país nos anos 1950, até o momento em que passa a atuar como escritor e intelectual desvinculado de instituições.

O segundo volume da autobiografia de Erico Verissimo, Solo de Clarineta (1976), obra publicada postumamente em 1975, recebe neste breve espaço nossa maior atenção e interesse. Observaremos em diálogo com a referida obra - que em grande parte já havia sido revisada e impressa pelo autor antes de sua morte (VERISSIMO, 1976, s.p) - como a reconstrução de suas memórias sobre a visita a Portugal no ano de 1959 dialoga com o tumultuado contexto autoritário no Brasil dos anos 1970 e reafirma sua consolidação como intelectual autônomo.

Quando se detém à carreira de Erico Verissimo, é central sua construção de escritor

2 A Good Neighbor policy foi implantada pelos Estados Unidos no governo do presidente Franklin Roosevelt no ano de 1933 e durou até o início da Guerra Fria, no ano de 1945. Tal política contemplou diversas ações em diferentes áreas como a indústria, a agricultura, a cultura - implementadas pelo governo norte-americano, a fim de que se alinhasse os interesses da América Latina aos interesses dos Estados Unidos. Mais sobre a política de Boa Vizinhança e o Brasil ver: TOTA, Antonio Pedro. O imperialismo sedutor: a americanização do Brasil na época da Segunda Guerra. São Paulo: Companhia das Letras, 2000. 
vinculada à de intelectual autônomo, e cuja trajetória está permeada pelas diferentes funções que desempenhou ao longo da carreira. Em 1931 em Porto Alegre, Erico inicia sua carreira como coordenador da Revista do Globo, da então Livraria do Globo, onde ainda passou a atuar como tradutor e conselheiro literário, além de escritor, até 1954, ano em que se desvincula formalmente da editora. As funções desempenhadas na Editora Globo não se restringiam ao contexto brasileiro, uma vez que sua importância o impulsiona a um diálogo em uma rede nacional e internacional ${ }^{3}$ de artistas e intelectuais que influencia diretamente a construção de sua carreira e atuação.

No final do ano de 1940, já bem inserido no espaço público nacional, também por conta do sucesso de recepção do romance Olhai os lírios do campo em 1938, que inclusive lhe permitiu viver de direitos autorais, Erico é convidado pelo Departamento de Estado norte-americano para atuar na política de Boa Vizinhança como agente cultural.

O convite por parte do Departamento do Estado norte-americano foi assinado por Mr. Cordell Hull - então Secretário de Estado - e contemplou a estadia de Erico nos Estados Unidos por três meses. Durante este período, o escritor viajaria para mais de dez cidades norte-americanas, daria diversas palestras sobre o Brasil, literatura e relações inter-americanas em universidades e centros de ensino e educação, e se encontraria com escritores, professores e figuras políticas brasileiras, norte-americanas e de outras nacionalidades.

Após sua primeira estadia nos Estados Unidos, Erico Verissimo retorna ao Brasil no dia 21 de maio de 1941 e publica sua primeira narrativa de viagem Gato preto em campo de neve pela Editora Globo em novembro do mesmo ano. Na referida obra, Erico trata de sua experiência no país em diálogo com aspectos políticos, históricos e literários neste contexto mais amplo da política de Boa Vizinhança, ou seja, que envolve não só o Brasil e os Estados Unidos, mas suas relações com outros países da América Latina e Europa. É importante ressaltar que Gato preto em campo de neve vendeu antes do primeiro mês após seu lançamento uma tiragem de 10 mil exemplares. Já no ano da estreia do livro, mesmo que em novembro de 1941, foram feitas duas impressões da primeira edição, uma de 10 mil exemplares e mais outra de 5 mil exemplares ${ }^{4}$.

O segundo convite que Erico Verissimo recebe no período da política de Boa Vizinhança foi em 1943, quando é convidado para dar um curso sobre literatura brasileira na Universidade da Califórnia, em Berkeley. Após o aceite, Erico embarca em setembro daquele ano, desta vez com a família toda (sua esposa Mafalda e seus dois filhos, Luís Fernando e Clarissa), para uma estadia de dois anos nos Estados Unidos, permanecendo até setembro de 1945. Lá ele leciona o curso de literatura brasileira na Universidade da Califórnia por 8 meses e, após este período, integra a programação de atividades culturais no Mills College

3 “[...] no início dos anos 1940 [a Editora Globo] já era a segunda maior editora do país, o que implicava em inúmeras vantagens de ordens diversas, como quanto à publicação e distribuição de suas obras, até a rede de contatos em que o escritor se encontrava e construía, em especial graças à influência política que a editora foi exercendo ao longo dos anos no Brasil e internacionalmente." (BOECHAT, 2017, p. 60). Mais sobre a Editora Globo ver: BATISTA, Karina Ribeiro. A trajetória da Editora Globo e sua inserção no campo literário brasileiro nas décadas de 1930 e 1940. 226 f. Tese (Doutorado em Teoria da Literatura), Universidade Pontifícia Universidade Católica do Rio Grande do Sul, Porto Alegre, 2008.

4 No volume O contador de histórias (CHAVES, 1972, p. XX), tem-se o seguinte levantamento: da obra Gato Preto em campo de neve houve 10 impressões da primeira edição (até o ano de 1957) - contabilizando 43 mil exemplares - e uma impressão da segunda edição de 15 mil exemplares (em 1963), totalizando 58 mil exemplares até o referido ano. 
por pouco mais de um mês. Depois disso, muda-se para Hollywood, cidade em que permanece até o final de sua estadia nos Estados Unidos e período em que cumpre uma agenda de compromissos - entre eles palestras em instituições de ensino e programas de rádio - sob o patrocínio do Office of War Information em vista do war effort ou "esforço de guerra".

A volta do gato preto, então, é a segunda e última narrativa de viagem sobre os Estados Unidos e foi publicada no Brasil apenas em 1946, não mais imediatamente após o retorno do escritor ao país como no caso do primeiro livro ${ }^{5}$. Assim como na primeira narrativa, em $A$ volta do gato preto Erico trata da relação da literatura com aspectos políticos e históricos de maneira ampla, mas principalmente relacionados ao contexto em que o autor se inseria. A grande diferença é que naquele momento os Estados Unidos e o Brasil já haviam declarado guerra aos países do Eixo, o que influencia diretamente sua motivação para a nova estadia no país com a família.

No primeiro volume de sua autobiografia Solo de clarineta, Erico (1973, p. 280) faz referência ao segundo convite como oportunidade para "respirar ares mais livres", o que se tornava cada vez mais difícil no então Estado Novo de Vargas:

[n] aquele mesmo ano me chegou um novo convite do Departamento de Estado, dessa vez para dar um curso de literatura brasileira numa universidade dos Estado Unidos, à minha escolha. (Correu então o tolo rumor de que o clero havia conseguido por esse meio mandar-me para o exílio.) Exasperado, decepcionado, triste ante a situação brasileira, decidi aproveitar a oportunidade para me afastar de meu país por algum tempo, respirar ares mais livres e descansar de toda aquela choldra estado-novista. Escolhi a Universidade da Califórnia que, consultada, me aceitou. Mudei-me para Berkeley com toda a família, em setembro de 1943. O que foram os dois anos que passamos entre San Francisco e Los Angeles está narrado no livro A volta do Gato Preto.

A partir do excerto destacado, vale mencionar que Erico já no início da carreira se pronuncia publicamente a respeito de sua posição política, como quando em 1935 ele lidera um manifesto antifascista ${ }^{6}$ voltado não só ao contexto nacional, mas também ao fascismo italiano e alemão 7 . Outro dado importante é que, após a publicação de Caminhos cruzados no mesmo ano, tem-se a reação do clero católico no contexto brasileiro, que considerou o

5 Segundo Chaves (1972, p. XX), de A volta do gato preto tem-se 4 impressões da primeira edição - contabilizando 30 mil exemplares até 1957 - e a primeira impressão da segunda edição, de 15 mil exemplares (de 1962), totalizando 45 mil exemplares até o referido ano.

$6 \mathrm{O}$ documento mencionado continha um protesto direto e veemente contra a invasão da Abissínia pelas tropas de Mussolini.

7 As ações anti-fascistas e anti-nazistas de Erico Verissimo foram propagadas também nos Estados Unidos, como em matéria do jornal norte-americano Los Angeles Times de 18 de abril de 1941: "Verissimo since 1934 has been writing against the Fascists. Like many another liberal he was decried as a Communist when he attacked Fascistic tendencies, but he insists he has a little use for one as the other." Em tal matéria, além disso, Erico Verissimo é apresentado como integrante da política de Boa Vizinhança, escritor, membro da Editora Globo e tradutor de literatura norte-americana. Cf. BRAZILIAN novelist tells plan to foster Western Harmony. Los Angeles Times, Los Angeles, p. 1A, 18 abr. 1941. 
livro, segundo Erico (1973, p. 256), “imoral, subversivo, dissolvente, tudo isso, imagino, porque não só ousava mostrar o medonho contraste entre os muito ricos e os muito pobres, como também porque expunha as mazelas morais de certas camadas de nossa burguesia $[\ldots] "$.

Mesmo após o término oficial das ações da política de Boa Vizinhança, Erico Verissimo continua suas estreitas relações com os Estados Unidos em meio à política exterior. Assim, sua terceira e última estadia no país deu-se entre 1953 e 1956, quando assumiu a direção do Departamento de Assuntos Culturais da antiga Pan American Union, hoje Organization of American States ou "Organização dos Estados Americanos” (OEA), em Washington D.C., sucedendo o brasileiro Alceu Amoroso Lima. Ao longo desses 3 anos, o autor dá continuidade ao engajamento nas relações inter-americanas em vista da produção cultural e lida com processos de publicação de seus livros nos Estados Unidos ${ }^{8}$.

A exemplo da inserção internacional de Erico Verissimo é possível identificar outros movimentos migratórios de artistas e intelectuais também a partir de políticas internacionais, como foi o caso da política de Boa Vizinhança estadunidense, que impulsiona o trânsito já antes do eclodir da Segunda Guerra e ganha espaço à medida que o contexto político vai se tornando mais tenso. Essas movimentações também aconteceram por períodos menores de tempo, como foi o caso de Villa Lobos e Sérgio Buarque de Holanda que estiveram nos Estados Unidos por estadias curtas - recebidos inclusive por Erico Verissimo -, mas também por períodos mais extensos, como foi o caso de Thomas Mann, que imigra para o país em 1938 e permanece até $1952^{9}$.

Essa rede de sujeitos atuantes e em trânsito compõe uma constelação em que também as obras ${ }^{10}$ podem ser consideradas atuantes. No sentido de Bruno Latour (2012) e de sua Teoria do Ator-Rede, podemos identificar uma worknet ${ }^{11}$, ou "uma rede em trabalho", em

8 A principal editora que publicou os livros de Erico Verissimo nos Estados Unidos foi a editora norte-americana MacMillan Co., na qual também passou a atuar como conselheiro literário para assuntos sul-americanos em 1945. Mais sobre o convite da MacMillan ao autor, ver: VERISSIMO, Erico. [Carta] 2 mar. 1945, [para] BERTASO, Henrique, p. 2. Disponível em: IMS 068102.

9 A obra Gato preto em campo de neve é dividida por capítulos que descrevem a agenda de Erico Verissimo em determinadas cidades nos Estados Unidos e por capítulos que descrevem alguns de seus encontros com escritores e intelectuais, dentre eles Thomas Mann. Mais sobre o encontro com Mann ver: PAULINO, Sibele; SOETHE, Paulo Astor. Thomas Mann e a cena intelectual no Brasil: encontros e desencontros. Pandaemonium germanicum. n.14, p. 28-53, fev. 2009.

10 Aqui consideramos inclusive a tradução de diversas obras, como aquelas que foram traduzidas por Erico Verissimo durante sua atuação na Editora Globo, também a partir de incentivos previstos pela política de Boa Vizinhança. Em tal política previa-se projetos de assistência à tradução. Mais sobre o assunto, ver no seguinte relatório: HANKE, Lewis. Report on the project to assist the translation of United States books into Spanish and Portuguese and their publication in Latin America. 1942, p. 36-37. Disponível em: SIA, Record Unit 7091, Series 16, Box 419, Folder 11.

Em documentário sobre a vida e a obra de Erico Verissimo tem-se a informação que entre 1925 e 1930 foram feitas 48 traduções de obras de ficção pela Editora Globo, enquanto que entre os anos 1930 e 1937 tem-se 213 traduções. A maioria das traduções de língua inglesa publicadas pela editora foram feitas por Erico Verissimo e por Monteiro Lobato. Cf. DVD. ATRICHER, Luzimar. 2005. Disponível em: IMS 6516 / BR IMS CLIT EV Da.

11 Aqui em contraposição à ideia de Network, que seria "uma rede de trabalho" estabilizada por intermediários. Nas palavras de Latour, "[w]ork-nets nos permitira avaliar quanto trabalho é necessário para lançar net-works: as primeiras como mediadores ativos, as segundas como conjunto estabilizado de intermediários.” (LATOUR, 2012, p. 193) 
que pessoas e objetos atuam como mediadores que transportam significados em um social construído de associações ao passo que são também instâncias que podem transformar, traduzir, modificar e até distorcer significados.

Nesse sentido, Erico parece ter identificado a atuação de sua primeira narrativa de viagem sobre os Estados Unidos em carta a Mr. Pattee, datada de 29 de dezembro de $1941^{12}$, em que comenta o sucesso de vendas e os efeitos provocados nos leitores ao afirmar que verifica com alegria "que com meu último livro consegui muitos adeptos para o pan-americanismo" e que havia sido muito sincero quanto às suas descrições dos Estados Unidos, atribuindo a esta sinceridade o sucesso da obra.

De acordo com o que expomos brevemente aqui, nota-se que na carreira de Erico Verissimo o papel político do autor e de sua obra no espaço público ocupam um lugar central, seja por meio da análise mesmo dos textos literários de sua autoria ou ainda quando nos detemos às diversas entrevistas, correspondências e declarações no cenário nacional e internacional. Não se trata de assumir, contudo, uma produção literária de mensagem ou propaganda, mas sim de conciliar sua ação por meio do texto literário e proferimentos no espaço público de modo mais complexo. Erico, segundo nossa compreensão, reconhece seu trabalho como ofício político porque em princípio já se reconhece como um sujeito político. No sentido em que menciona Edward Said (2005, p. 34), “a política está em toda parte”. Dessa forma, o autor também identifica na natureza do texto literário uma potencialidade que pode ampliar esta voz política, ao passo que tem claro em que medida sua consolidação como escritor também lhe dá a oportunidade de se consolidar como figura pública atuante.

Entendemos, dessa forma, haver certa fusão entre literatura e política, ou escritor e político. Erico, contudo, não se aproxima do estereótipo do escritor engajado ou da literatura engajada. Em diálogo com o crítico Daniel Fresnot (1977, p. 83), “[a] imagem do contador de histórias ficou, e com o passar do tempo seu conteúdo profundo foi se tornando cada vez mais claro".

Erico Verissimo alia o tecer da escrita literária à compreensão política que nela pode ser explorada, seja em vista do texto em si, seja em vista do lugar que sua produção o proporcionou no espaço público ao longo da carreira. Dessa maneira, a partir de uma análise atenta à sua vasta obra, é possível identificar como o escritor explora as características dos gêneros literários, inclusive, em consideração aos diferentes contextos políticos em que se inseriu ao longo da carreira, como é o caso das narrativas de viagem sobre os Estados Unidos, e também sobre o México e Israel ${ }^{13}$.

Tal consciência que identificamos ter tido o escritor nos é perceptível em especial nos dois volumes de sua autobiografia, já que ele se posiciona de modo claro e direto a respeito de sua então compreensão política, até mesmo revelando como se deu o desenvolvimento e construção dessa compreensão ao longo da carreira.

No segundo volume de Solo de Clarineta, que recebe nossa atenção aqui, Erico dedica longo capítulo para narrar sua viagem a Portugal no ano de 1959, ocasião em que visita

12 Cf. VERISSIMO, Erico. [Carta] 29 dez. 1941 [para] PATTEE, Richard. Disponível em: IMS 069334.

13 Aqui, quanto ao gênero narrativa de viagem, poderia ser explorado o conceito "friccionalidade", em alemão "Friktionalität", do romanista alemão Ottmar Ette (2001, p. 28), a saber, o que o teórico define como certa hibridez de tal gênero, uma "coordenação da precisão científica e da imaginação poética na narrativa de viagem". 
o país na companhia de sua esposa e filho e por conta própria, como hóspede do editor Antônio de Souza Pinto. Ao longo de sua estadia, o escritor, já muito popular também em Portugal, profere diversas palestras em diferentes cidades e posiciona-se publicamente e de modo bastante crítico contra o regime autoritário de Oliveira Salazar.

Neste momento mais avançado da carreira, fica evidente que o autor é um sujeito que se interessa pelas causas humanas, identificando-se como parte ativa desta humanidade. Aproxima-se de seus leitores interessado em um processo de interação que passa pela recepção de suas obras, crente em melhor compreender as aflições, as necessidades, os medos, as alegrias, as dinâmicas sociais e as relações de poder. Logo, Erico não abandona o lugar proporcionado graças ao sucesso de sua obra, e faz uso deste lugar para propagar suas convicções em vista de um papel social. Dessa forma, seus pronunciamentos nos diversos ambientes que frequentou motivam não somente a crítica do público ao regime salazarista, mas também vão ao encontro de um público que também luta pelo fim de tal regime.

Neste momento da carreira temos um Erico Verissimo que se consolida como exemplo de intelectual fruto da modernidade, moldado em especial na França da segunda metade do século XIX. A exemplo de Charles Baudelaire, o escritor brasileiro se coloca no papel de flâneur, um contemplativo, mas também um crítico. Trata-se de um intelectual que se engaja nas causas particulares em prol dos valores universais, como a liberdade e a justiça, à moda de Émile Zola.

Vale observar, além disso, que o escritor reconhece que o sujeito engajado precisa estar desvinculado de instituições e fazer parte de um campo intelectual autônomo. Assim, por meio de sua consolidação como escritor, e a partir de seu desligamento da Editora Globo em 1954 e de todos os cargos políticos que assumiu, ele ocupa um espaço nessa esfera pública que se afasta da subserviência e bajulações, busca incessantemente independência e emancipação, e distancia-se cada vez mais da "rede esmagadoramente poderosa de autoridades sociais" (SAID, 2005, p. 16).

A análise da narrativa sobre a viagem a Portugal cabe perfeitamente para que se observe as características desse intelectual autônomo. Mesmo anos após a visita, a valoração política de sua presença em Portugal ainda é objeto de suas preocupações, o que nos parece claro quando ele publica - ou melhor, planejou publicar, uma vez que se trata de uma obra póstuma - tal experiência de viagem no cenário do Brasil autoritário dos anos 1970.

Assim, Erico se pronuncia com franqueza em Portugal diante do público na ocasião de uma de suas palestras, a fim de que não restem dúvidas sobre sua posição política, seja ao fazer referência ao então contexto português ou em vista daquele que receberá o segundo volume de Solo na metade dos anos 1970 no Brasil:

Falei. Segui a rotina, da qual já estava enfarado. Tive a impressão de estar contando mentiras - o que não era verdade. Finalmente, para que as autoridades civis, militares e eclesiásticas não tivessem ilusões a meu respeito, falei contra os governos totalitários e dissertei sobre a necessidade que tem todo homem de liberdade. Liberdade de credo, de reunião, de locomoção, de acesso às fontes de informação. E - que diabo! — liberdade para escolher seus governantes! Depois veio o período de perguntas e respostas, que me deu a oportunidade de dei- 
xar ainda mais clara minha posição política. E a conferência me saiu mais longa do que eu esperava e desejava. E do que minha canseira permitia. (VERISSIMO, 1976, p. 215-216)

A clareza de seu posicionamento está posta também em outros momentos da obra em que relata seus pronunciamentos públicos. Além de se colocar de modo veemente contra a censura, a favor da liberdade e da democracia, Erico faz referência a seus pares, de certa forma apoiando-os, como quando menciona o escritor Jorge Amado, também conhecido pelo público quanto ao ativismo no Partido Comunista.

Destacamos o seguinte fragmento:

[c]hega a minha vez de discursar, agradecendo em nome de minha mulher e no meu a homenagem que nos acaba de ser prestada. Ataco com lerdo e sonolento ímpeto os governos totalitários, a censura, a tortura e digo de minha esperança de, na nossa próxima visita ao Porto, encontrar Portugal liberto de seus opressores. [...] Que devemos fazer diante deste ou daquele problema? Respondo com a maior franqueza. Lutar, lutar, lutar sempre, sem esmorecer. Este país pertence a seu povo e não a dezoito ou vinte famílias abastadas. Todas as tiranias caem, mais tarde ou mais cedo. Ninguém é dono de ninguém.

À medida que o tempo e as perguntas passam, mais claras e diretas se vão fazendo as referências ao regime político português. Alguém da plateia pergunta qual é o escritor mais popular do Brasil, e quando pronuncio o nome de Jorge Amado, a plateia rompe em aplausos e vivas frenéticos. (Em 1959 os livros do autor de Terras do Sem Fim estavam proibidos de circular em Portugal.) (VERISSIMO, 1976, p. 166-171)

Cabe mencionar a partir do fragmento citado, como Erico é capaz de observar o cenário político de modo crítico, uma vez que inclusive se aproxima do Partido Comunista por meio da menção a Jorge Amado, mesmo que ele próprio nunca tenha se filiado a tal partido e, inclusive, tenha criticado em diferentes ocasiões a luta em nome de um partido político específico.

Neste momento da carreira, como observamos anteriormente, o autor já não cede às pressões das instituições, mesmo quando ele mesmo é chamado em particular a fim de que sejam evitados seus prováveis pronunciamentos contrários ao regime de Salazar. Como quando o autor (VERISSIMO, 1976, p. 91-92) relata que, na primeira conferência pública no Teatro D. Maria II, um homem de grande simpatia pessoal, o administrador do teatro, pede-lhe que, “[...] por favor, meu amigo, não acenda nenhum fósforo. Compreende o que lhe estou pedindo?” A resposta de Erico, descrita em suas memórias, foi um sinal afirmativo com a cabeça sem que tenha prometido nada, e vai ao longo da narrativa tomando dimensões concretas. Nos anos 1959, depois da Era Vargas e o Estado Novo no Brasil, Erico se sente bastante à vontade para se contrapor a cenários políticos em vista da censura e a favor 
da liberdade, inclusive em vista de ações políticas que envolvem os Estados Unidos ${ }^{14}$.

Central na narrativa sobre a visita de Erico a Portugal é compreendê-la como uma resposta a ações de integrantes do regime salazarista e da política norte-americana, que talvez estivessem até mesmo agindo em diálogo, como podemos observar a partir dos relatos do próprio escritor e também em documentação emitida pela Embaixada dos Estados Unidos em Lisboa ao Departamento de Estado em Washington D.C..

Logo no início da estadia em Portugal, Erico recebe um bilhete do amigo Maurício Rosenblatt acompanhado de um recorte do Correio do Povo de Porto Alegre. Segundo a descrição de Erico (1976, p. 90-91), temos:

[d]ias mais tarde recebi do Brasil, da parte de Maurício Rosenblatt, um bilhete acompanhado dum recorte do Correio do Povo de Porto Alegre, contendo uma curta notícia distribuída pela United Press International e na qual se informava que o "romancista brasileiro" se encontrava em Lisboa como hóspede oficial do Governo português. Essa inverdade me deixou irritado. Não sou homem de grandes explosões, mas de pequenas implosões. Telefonei imediatamente para a agência local da U.P.I., pedi à operadora que chamasse seu gerente. Quando o tive na outra extremidade da linha e ouvi o seu "Está lá?», identifiquei-me, minuciosamente, li em voz alta e tão clara quanto possível, a notícia do recorte, e acrescentei: "Exijo que essa agência desminta o mais cedo possível este comunicado. Não é verdade que eu esteja em Portugal como convidado do governo salazarista. Viajo por conta própria e neste país sou hóspede de meu editor Antônio de Souza Pinto. Jamais aceitei nem aceitarei qualquer favor dum governo totalitário". Meu invisível interlocutor murmurou apenas: "Pois pois...” Desliguei o telefone. Como uma agência de notícias da estatura da United Press International não pode enganar- se e muito menos admitir publicamente que cometeu um erro de informação, a maneira que o citado gerente encontrou para "restaurar a verdade" foi a de, no próximo comunicado que expediu para o Brasil a meu respeito, anunciar que "o escritor, que se encontra na Europa em viagem particular de recreio, pronunciará hoje à noite uma conferência pública no Teatro D. Maria II...” Ora, essa conferência seria a minha primeira prova de fogo em Portugal.

A difusão da notícia de que Erico estaria em Portugal como hóspede do então governo português, de acordo com a nota da "agência de notícias da estatura da United Press

14 Erico inclusive menciona nas memórias sua interlocução com o escritor português Miguel Torga: "A comida é simples. A companhia agradável. Os estudantes fazem-me perguntas. Como vai o Brasil? Que penso da construção de Brasília? Que rumo irá Fidel Castro dar à política interna de Cuba? Toleraria Tio Sam um regime socialista praticamente enredado em suas barbas?

Respondo que o Brasil vai bem, pois lá não existe censura. A construção de Brasília parece-me hoje uma extravagância, mas daqui a alguns anos eu serei possivelmente dos primeiros a reconhecer que no fim de contas a mudança da capital federal foi uma boa ideia. E acrescento: 'E o mais notável é que essa obra de proporções faraônicas está sendo executada sem trabalho escravo, sem nenhum tipo de opressão'. 'Quanto à Cuba, temo que a inabilidade diplomática dos Estados Unidos acabe por atirar Fidel Castro nos braços da Rússia Soviética'. Torga resmunga: 'É o que vai acontecer. São umas bestas, esses seus amigos americanos." (VERISSIMO, 1976, p. 138-139) 
International", reforça a sugestão, ou a pressão, para que ele "não acenda nenhum fósforo". A partir dessa informação, ademais, cabe observar que os interesses portugueses parecem estar alinhados com os dos Estados Unidos.

Como mencionado, identifica-se por meio de documentação oficial ${ }^{15}$ a preocupação por parte da diplomacia norte-americana com relação aos pronunciamentos de Erico Verissimo nas diversas conferências proferidas. Conforme relata Regina Zilberman (2007, p. 119), “o teor político de resistência [por parte de Erico Verissimo] ao regime [salazarista] é salientado pelos observadores norte-americanos". É curioso, além disso, e ainda em diálogo com Zilberman (2007), que o documento da Embaixada norte-americana, datado em 3 de março de 1959, é "assinado em nome de Charles Burke Elbrick (que, dez anos depois, sendo embaixador dos Estados Unidos no Brasil, foi sequestrado, no Rio de Janeiro, por membros do MR-8, dando início a um série de ações de militantes da esquerda contra a ditadura militar então vigente no país) [...]". Estariam aqui esboços do que se desenharia no contexto brasileiro nos anos 1960 ? $^{16}$

Erico, que ao longo da estadia resiste às investidas institucionais e governamentais, articula-se de modo ainda mais perspicaz. Não deixa de responder, então, em momento oportuno e por um meio de divulgação igualmente oportuno, a tais investidas. Conforme o autor (VERISSIMO, 1976, p. 251-252), no segundo volume de sua autobiografia, temos:

[d] epois do café e dos licores Paulo Cunha ergue-se para falar, o que faz com desembaraço, de maneira informal, sem arroubos oratórios. Entre outras coisas elogios ao Brasil e aos brasileiros - diz que seu "prezado V'rissimo" deve compreender que o conceito de liberdade varia de pessoa para pessoa, de época para época. O "caro escritor" deve ter visto como o povo português vive feliz e em paz, tem o que comer, o que vestir, onde morar e no que trabalhar. Esse povo não está interessado nos conceitos acadêmicos da palavra liberdade... (De vez em quando se ouve um brusco "Apoiado!") A oração não é longa e Paulo Cunha a encerra com as seguintes palavras: «Espero que ao voltar a sua pátria o romancista narre a seus compatriotas e leitores o que realmente viu e sentiu em Portugal". O orador senta-se ao som de entusiásticos e prolongados aplausos. Quando de novo se faz silêncio, levanto-me e limito meu "discurso" a uns três ou quatro minutos. [...] Quanto a contar no Brasil o que realmente vi e senti na terra do grande escritor, podem todos ficar descansados, pois é exatamente isso que pretendo fazer.

A nosso ver, ao reagir publicamente por meio de sua obra que seria publicada nos anos

15 Foreign Service Despatch, de 3 de março de 1959. Arquivo Público, Mariland, Viginia. Cf. ZILBERMAN, Regina. Erico Verissimo em Portugal - 1959. TriceVersa: Revista do Centro Ítalo-Luso-Brasileiro de Estudos Linguísticos e Culturais. Assis, n.1, v.1, p.115-128, maio-out. 2007.

16 A influência política dos Estados Unidos no Brasil junto a políticas autoritárias estende-se por longos anos, até mesmo em vista do golpe militar de 1964. Segundo Tota (2014, p. 297), "[a] historiografia mais recente tem produzido estudos sobre os últimos dias de Goulart no governo e, em especial, sobre o papel dos Estados Unidos na colaboração com os golpistas. O trabalho de Carlos Fico procura uma análise objetiva na presença americana nos preparativos dos acontecimentos de março e abril de 1964." 
1970 no Brasil, no contexto do regime autoritário brasileiro após o golpe militar de 1964, Erico não só responde ao então regime autoritário português, reafirmando a consciência que possui de seu lugar na carreira como intelectual, também graças à sua obra, mas demonstra que reconhece o potencial da inserção discursiva de sua obra.

Esse lugar que a obra lhe proporciona para atuar como intelectual é identificado pelo autor, por exemplo, quando ele (VERISSIMO, 1976, p.172) narra sua felicidade em escutar de um homem português de meia-idade que seus proferimentos lhe representavam como que uma "fresta da janela pela qual entra ar fresco, a luz do sol da liberdade, e então nós avistamos uma nesga de céu azul... e a esperança!" ou quando se alegra ao sentir que aqueles que o recebem em Portugal talvez nunca tenham lido um livro seu, mas reconhecem nele um "companheiro de lutas democráticas" (VERISSIMO, 1976, p. 210-211).

O escritor, o ficcionista, por outro lado, e como já mencionamos em diálogo com Fresnot, sempre se sobressai. Assim, é seu público leitor que está em grande medida em suas plateias, como quando o indagam sobre o destino de suas personagens:

“O Érico V’rissimo vai continuar a história da menina Clarissa?" - Um gordo cidadão de bela calva lustrosa queria saber se o Cap. Rodrigo Cambará existira na vida real ou era "um produto da imaginação de V. Ex.a". [...] E de repente me veio, vagamente desconcertante, a impressão de que estivera todo aquele tempo a assinar cheques sem fundo, enganando aquela boa gente, e que por isso estava sendo procurado por essa espécie de Interpol que muitos de nós trazem dentro de si mesmos, e que nos persegue de modo implacável, como no meu caso particular. Possivelmente um desses agentes secretos agora me esperava à porta, para me algemar... (VERISSIMO, 1976, p. 96-97)

A força da presença de suas personagens, mesmo que Erico descreva seu desconcerto, sua impressão "de que estivera todo aquele tempo a assinar cheques sem fundo", é recorrente em outras ocasiões, como quando menciona a visita às províncias ao norte do Tejo, em que lhe fizeram "indagações comovedoras sobre o destino de várias personagens de meus romances, como se se tratasse de criaturas da vida real” (VERISSIMO, 1976, p. 214).

A discussão sobre ficção e realidade em vista da produção literária, contudo, que é posta na narrativa em tom despojado, é, a nosso ver, sustentada pelo reconhecimento do potencial da linguagem em literatura. Assim podemos perceber na passagem que segue:

[e]stou vendo a cena, pois li esse romance mais de cinco vezes, em diversas épocas da minha vida. Jorge de Sena mostra-nos um sobrado esbelto de dois andares e diz: "Pela descrição do romancista, podemos deduzir que esta era a casa de Amelinha onde o P.e Amaro hospedou-se". Contemplo o sobradinho com uma ternura meio desconfiada e tento confrontar o que vejo com a imagem da residência da $S$. Joaneira que guardo na memória. Concluo que uma das vantagens do livro sobre os meios de comunicação audiovisuais é a de que no caso destes últimos a imaginação do espectador fica irremediavelmente presa ao que vê e ouve, ao passo que a cada releitura dum romance o leitor imagina as personagens, as cidades, as 
ruas, as casas e seus interiores de maneira diferente, embora as palavras do autor da narrativa permaneçam as mesmas. (VERISSIMO, 1976, p. 124-125)

A maneira que a linguagem em literatura opera, e cujos efeitos não podem ser previsíveis até mesmo em um mesmo leitor, é observada por Erico também no sentido de que esse discurso ficcional é capaz de incidir no contexto extraliterário. A nosso ver, portanto, trata-se de compreender a linguagem também em literatura como um medium de construção - um ambiente e instrumento - capaz de atuar no espaço social das relações humanas ${ }^{17}$. Erico (1976, p. 199), no excerto a seguir, descreve em suas memórias o seguinte depoimento:

Em dado momento levanta-se um senhor de meia-idade, baixo e frágil, que me interroga: "Acredita V. Ex.a que um romance pode ter a força de mudar a vida da pessoa que o lê?» Faço uma careta de ceticismo. "Minha tendência é responder pela negativa" - digo. — "Pelo menos não conheço nenhum caso..." O homenzinho sorri. "Pois é com prazer que lhe conto a estória de meu próprio filho, que estava estudando engenharia na Universidade de Coimbra. Um dia leu o romance de V. Ex.a, Olhai os Lírios do Campo, identificou-se de tal modo com a personagem principal masculina, o Dr. Eugênio Fontes, e passou a interessar-se de tal modo pela profissão médica, que decidiu deixar a engenharia para estudar medicina. Hoje em dia está formado, tem uma excelente clínica e sente-se perfeitamente realizado na sua profissão". Que pode dizer este autor de estórias imaginárias senão que se rende diante desse fato da vida real?

O potencial da linguagem, das palavras, tem na carreira de Erico Verissimo um lugar central, assim como procuramos expor brevemente aqui em diálogo com a atuação do autor também no espaço público por meio de seus proferimentos. São em suas memórias, por meio de sua voz e palavra, representada primeiro por sua produção literária, que ele reconhece o potencial que elas têm. Logo, formula e responde no final da carreira perguntas relevantes que permeiam como um Leitmotiv toda sua obra.

Concluímos, por fim, junto a Erico (1976, p. 229) que "se palavras podem mesmo ajudar alguém, creio que ajudei um pouquinho aqueles rapazes e raparigas de Beja." E encoraja-os: “[n]ada nos cai do céu' - lembro-me de ter-lhes dito com ênfase. — 'É preciso a gente lutar. E não devemos cessar de nos perguntar a nós mesmos: Quem sou eu? Que desejo realmente da vida?'”

17 Medium aqui segundo o filósofo alemão Karl Otto-Apel (2000). Trata-se da linguagem não somente como meio no sentido de instrumento de mediação, mas como ambiente onde se dão relações interpessoais. Compreende-se a linguagem como condição de possibilidade e também como forma de vida. 


\section{REFERÊNCIAS BIBLIOGRÁFICAS:}

APEL, Karl-Otto. Transformação da Filosofia I: Filosofia Analítica, Semiótica, Hermenêutica. Tradução de Paulo Astor Soethe. São Paulo: Edições Loyola, 2000.

Transformação da Filosofia II: o a priori da comunidade de comunicação. Tradução de Paulo Astor Soethe. São Paulo: Edições Loyola, 2000.

BATISTA, Karina Ribeiro. A trajetória da Editora Globo e sua inserção no campo literário brasileiro nas décadas de 1930 e 1940. 226 f. Tese (Doutorado em Teoria da Literatura), Universidade Pontifícia Universidade Católica do Rio Grande do Sul, Porto Alegre, 2008.

BOECHAT, Fernanda Boarin. O vaivém dum gato: interfaces entre ficção e realidade nas narrativas de viagem Gato preto em campo de neve e A volta do gato preto de Erico Verissimo. $415 \mathrm{f}$. Tese (Doutorado em Letras), Universidade Federal do Paraná, Curitiba, 2017.

BRAZILIAN novelist tells plan to foster Western Harmony. Los Angeles Times, Los Angeles, p. 1A, 18 abr. 1941.

CHAVES, Flávio Loureiro. (Org.) O contador de histórias: 40 anos de vida literária de Erico Verissimo. Porto Alegre: Globo, 1972.

DVD. ATRICHER, Luzimar. 2005. Disponíel em: IMS 6516 / BR IMS CLIT EV Da.

ETTE, Ottmar. Literatur in Bewegung: Raum und Dynamik grenzüberschreitenden Schreibens in Europa und Amerika. Göttingen: Hubert \& Co, 2001.

Foreign Service Despatch, de 3 de março de 1959. Arquivo Público, Mariland, Viginia.

FRESNOT, Daniel. O pensamento político de Erico Verissimo. Rio de Janeiro: Graal, 1977.

HANKE, Lewis. Report on the project to assist the translation of United States books into Spanish and Portuguese and their publication in Latin America. 1942, p. 36-37. Disponível em: SIA, Record Unit 7091, Series 16, Box 419, Folder 11.

LATOUR, Bruno. Reagregando o social: uma introdução à teoria do Ator-Rede. Tradução de Gilson César Cardoso de Sousa. Salvador: EDUFBA, Bauru: EDUSC, 2012.

PAULINO, Sibele; SOETHE, Paulo Astor. Thomas Mann e a cena intelectual no Brasil: encontros e desencontros. Pandaemonium germanicum. n.14, p. 28-53, fev. 2009.

SOETHE, Paulo Astor. Eine Begegnung in Denver: Thomas Mann, Erico Verissimo - und Herbert Caro als Überbringer. In: MÜLLER, Gesine. (Org.) Verlag Macht Weltliteratur: Lateinamerikanische- 
deutsche Kulturtransfers zwischen internationalem Literaturbetrieb und Übersetzungspolitik. Berlim: Walter Frey, 2014

TOTA, Antonio Pedro. O imperialismo sedutor: a americanização do Brasil na época da Segunda Guerra. São Paulo: Companhia das Letras, 2000.

VERISSIMO, Erico. [Carta] 2 mar. 1945, [para] BERTASO, Henrique. Disponível em: IMS 068102.

VERISSIMO, Erico. [Carta] 29 dez. 1941 [para] PATTEE, Richard. Disponível em: IMS 069334.

. Gato preto em campo de neve. Rio de Janeiro: Editora Globo, 1956.

A volta do gato preto. 11. ed. Porto Alegre: Editora Globo, 1980.

. Olhai os lírios do campo. Porto Alegre: Editora Globo, 1985.

Solo de clarineta: memórias. Porto Alegre: Editora Globo, 1973. vol. 1.

. Solo de clarineta: memórias. Porto Alegre: Editora Globo, 1976. vol. 2.

ZILBERMAN, Regina. Erico Verissimo em Portugal - 1959. TriceVersa: Revista do Centro Ítalo-LusoBrasileiro de Estudos Linguísticos e Culturais. Assis, n.1, v.1, p.115-128, maio-out. 2007. 